\title{
Organizações Sociais do setor de saúde no estado de São Paulo: avanços e limites do controle externo
}

\section{Health sector Social Organizations in São Paulo State: external control advancements and limits}

\author{
Bernardo Seixas Pilotto \\ Mestre em Saúde Coletiva pela Unifesp, sociólogo (UFRP), Curitiba/PR, Brasil. \\ bernardopilotto@gmail.com
}

Virginia Junqueira

Doutora em Ciências pela USP, professora adjunta da Unifesp, Santos/SP, Brasil.

virginiajuol.com.br

Resumo: $\mathrm{O}$ acesso à assistência à saúde é uma das principais preocupações dos brasileiros. $\mathrm{O}$ estado de São Paulo foi pioneiro em implantar gestão da saúde via Organizações Sociais - OS. A análise de relatórios de dois órgãos de controle externo concernente ao desempenho das OS assinalou dificuldades na obtenção de informações e questionamentos da legalidade e da viabilidade dessa forma de gestão nos pareceres de tais órgãos, sem que se produzam mudanças políticas de rumo.

Palavras-chave: Organizações Sociais. Controle externo. Reforma de Estado. Gestão. SUS.

\begin{abstract}
Access to health care is one of the main concerns of Brazilians. The State of São Paulo pioneered, in 1998, implanting health management by the Social Organizations-OS. This article analyzes reports of two external control organs concerning the OS performance. There were difficulties in obtaining information. Legality and feasibility of this form of management have been questioned in external control organs reports, without producing any political management changes.
\end{abstract}

Keywords: Social Organizations. External control. State Reform. Management. Unified Health System. 


\section{Introdução}

gestão dos serviços públicos de saúde brasileiros tem ocupado a or-
dem do dia dos acontecimentos, seja por problemas graves de acesso,
seja pelas propostas que versam sobre mudanças na administração do Sistema Único de Saúde (SUS). Conforme apontam pesquisas de opinião (Datafolha, 2013), a dificuldade de acesso à assistência à saúde continua como uma das maiores preocupações da população brasileira.

Como resposta a essa preocupação, em muitos casos as três esferas de governo têm optado pela desresponsabilização do Estado perante o sistema público de saúde, seja pela via direta da privatização, seja pela transferência da gestão para entidades de direito privado.

Apesar de a Constituição Federal de 1988 ter garantido o direito à saúde como um dever do Estado, é preciso reconhecer que desde a década de 1990, a implementação dessas garantias ocorreu num contexto de progressiva restrição do papel do Estado no âmbito dos direitos sociais. Foi nesse cenário que a execução pelo poder público da prestação de serviços de saúde passou a ser questionada e as propostas de terceirização pela via das Organizações Sociais vieram a ser apresentadas por governantes e intelectuais comprometidos com o ideário neoliberal.

Em 1998, foi aprovada a Lei federal n. 9.637 que qualificou entidades privadas como Organizações Sociais, permitindo que assumissem a gestão da assistência à saúde. No mesmo ano, o estado de São Paulo aprovou lei similar (Lei Complementar n. 846, de 4 de junho de 1998), sendo essa unidade federativa vanguarda na utilização dessa forma de gestão.

O debate sobre a melhor forma de implementação do SUS e sobre qual deve ser o modelo de gestão a ser utilizado, aqui incluso a análise das Organizações Sociais, tem sido travado por diversos autores, como Bahia (2008), Tanaka e Melo (2002), Montaño (2002), Granemman (2009), Correia (2011) e Cislagui (2010).

Na medida em que o poder público assume crescentemente o papel de regulador, e não mais de executor, destaca-se a importância de dispositivos e 
mecanismos de controle e regulação das entidades privadas que passam a operar a assistência à população. Para vários autores, mesmo para os que se posicionam como defensores do mercado, as questões ligadas à saúde, por não serem previsíveis e pela ausência das condições de "perfeita competição", devem sofrer intervenção mais presente do Estado. Assim, torna-se recomendável a atuação de controle externo às entidades prestadoras de serviço. Em outras palavras, o consumidor não é soberano, e é vulnerável, entre outras condições, a riscos e incertezas, à distribuição desigual da informação sobre a qualidade da assistência, à existência de barreiras no acesso e às chamadas "externalidades" (Ocké-Reis, Andreazzi e Silveira, 2005).

Após dezoito anos da implementação da lei que instituiu as OS (Brasil, 1998), faz-se necessário analisar criticamente a capacidade regulatória dos órgãos externos ao Poder Executivo, que devem cumprir o papel de controle no processo de mudança da gestão.

Para tal, foi realizada uma pesquisa qualitativa cujo objeto foi o desempenho de dois órgãos externos de controle que examinam e emitem parecer sobre a performance das OS do setor saúde no estado de São Paulo, escolhido por ter sido pioneiro na implementação do modelo no Brasil.

Tal metodologia, surgida das investigações das ciências sociais, diferencia-se dos estudos quantitativos, visto que a abordagem qualitativa, segundo Triviños (1987, p. 137),

desenvolve-se em interação dinâmica, retroalimentando-se, reformulando-se constantemente, de maneira que, por exemplo, a coleta de dados num instante deixa de ser tal e é análise de dados, e esta, em seguida, é veículo para nova busca de informações.

Foram selecionados, entre os órgãos externos de controle da gestão por OS no estado de São Paulo: o Tribunal de Contas do Estado de São Paulo (TCE) e a Assembleia Legislativa do Estado de São Paulo (Alesp). Em seguida foram identificadas e analisadas as modalidades de publicização das informações concernentes à gestão por OS, tanto nas páginas eletrônicas da SES/SP, quanto dos órgãos de controle selecionados. 
Visando contribuir para a investigação crítica do modelo de Organizações Sociais, foram identificados e examinados dois documentos dos referidos órgãos externos de controle, cujo conteúdo avaliou a gestão de hospitais pelas OS e as ações de monitoramento, acompanhamento, fiscalização e auditoria desenvolvidas pela Secretaria de Estado de Saúde de São Paulo (SES/SP) entre 2008 e 2012: um relatório do TCE e um relatório produzido em 2008 pela Comissão Parlamentar de Inquérito - CPI — da Alesp, cujo objeto foi a Remuneração dos Serviços Médico-Hospitalares. Tratando-se de uma análise documental, não há pretensão de generalizar os resultados obtidos.

Um fator decisivo para a escolha desses documentos foi a dificuldade de acessar fontes de informação de outros órgãos, bem como de realizar entrevistas diretamente com trabalhadores e gestores das Organizações Sociais, situação apontada também por Coneglian (2013).

\section{Resultados}

No âmbito do Tribunal de Contas do Estado de São Paulo, a Diretoria de Contas do Governador desenvolveu um estudo, em 2010, comparando seis estabelecimentos hospitalares estaduais de mesmo porte e complexidade com gestão pela administração direta e por Organizações Sociais (São Paulo, 2010). Dentre os fatores que pressionaram para a produção dessa investigação, pode-se creditar a ocorrência da CPI que abordou a gestão hospitalar sob controle da SES/SP, além dos resultados da análise das contas do governo estadual e o posicionamento contrário à gestão por Organizações Sociais por parte do Conselho Estadual de Saúde de São Paulo.

Diante da dificuldade em comparar a gestão de hospitais, foram selecionados três pares de hospitais a serem cotejados, considerando o mesmo porte e complexidade similar e também a localização na mesma região de saúde. A adoção desse método restringiu o número de hospitais a serem analisados, visto que "das 64 regiões de saúde do estado de São Paulo, em apenas seis coexistiam hospitais gerenciados pela administração direta ou por Organização Social” (São Paulo, 2010, p. 33). 


\section{Destaques do relatório do TCE/SP (2011)}

Os hospitais vinculados à administração direta tinham maior quantidade de equipamentos de diagnósticos por imagem e exames, como raio $\mathrm{X}$ e ultrassom, quando comparados aos hospitais geridos por Organizações Sociais. Isso reforça a hipótese, levantada por Andreazzi e Bravo (2014), que a gestão por OS serviria, também, para facilitar a compra de serviços no setor privado. Segundo as autoras,

sob o guarda-chuva do estatuto jurídico de organização sem fins lucrativos, exigência da legislação para ser certificada pelo Estado, abriga-se uma intensa contratação de serviços específicos para empresas lucrativas: o relatório se refere a "quarteirização" e até "quinteirização" dos serviços prestados. Ao terem a permissão de contratar todo tipo de serviços, sem controle público, o que ocorre é que empresas que prestam serviços hospitalares são convidadas a atuar dentro de hospitais públicos e subcontratam outras. (Andreazzi e Bravo, 2014, p. 507)

A compra de serviços (consultas, exames, internações, todo tipo de procedimentos) é feita pela administração direta e indireta (autarquias), via contratos, obedecendo a lei de licitações. Já as OS compram serviços sem licitação, pois são entidades privadas e, devido à própria estrutura dos hospitais, têm essa compra incentivada.

No âmbito da gestão, outros pontos do relatório do TCE ainda demandam análise. $\mathrm{Na}$ administração direta, o quadro de trabalhadores do Serviço Social é maior do que nos hospitais geridos por OS, permitindo depreender que o atendimento na administração direta tem maior proximidade com o conceito de integralidade, um dos princípios do SUS.

Em relação a salários, os cargos de gestão são mais bem remunerados nas OS do que na administração direta, mostrando que as OS acentuaram a estrutura hierárquica do serviço público, ainda que os documentos em defesa desse modelo de gestão argumentassem inversamente.

Sobre a rotatividade, a taxa é maior na administração direta para os cargos de "enfermeiro", "cirurgião-geral" e "pediatra”. Uma hipótese que explicaria 
esse achado é o fato de esses trabalhadores da administração direta estarem com salários abaixo da média do mercado, fazendo com que muitos profissionais dessa área "fujam" para o setor privado.

O estudo do TCE ainda registra que as OS possuem mais serviços terceirizados. Isso mostra que, ainda que muitas áreas da administração direta tenham sido terceirizadas nos últimos anos (como vigilância, limpeza e transportes), há uma preservação maior desses postos de trabalho na administração direta.

No âmbito do controle do SUS, o estudo verificou que tanto os hospitais geridos por OS, como pela administração direta, têm poucas ações auditadas e há falhas nos relatórios referentes à emissão de Autorização para Internação Hospitalar (AIH).

Por fim, no âmbito do que o estudo do TCE chama de "resultado econômico", ambos os modelos de gestão apresentam prejuízo. Isso acontece porque um dos princípios do SUS, que é seguido tanto pela gestão por OS como pela administração direta, é a gratuidade. Porém, ao analisar os dados mais a fundo, é possível verificar que os gastos são menores na administração direta, caso seja considerado o que é definido como "gastos tributários".

Isso acontece porque as entidades sem fins lucrativos, como as OS, são isentas da contribuição patronal para a Seguridade Social. Mas, como a contratação de trabalhadores pelas OS se dá pelo regime da Consolidação das Leis do Trabalho (CLT), a contribuição patronal tem que ser recolhida obrigatoriamente. Neste caso, esse gasto é feito pelo contratante (o governo do estado de São Paulo), enquadrado como um "gasto tributário". Considerando isso, o volume de gastos pode variar de aproximadamente $\mathrm{R} \$ 40$ milhões (no Hospital Geral de Guaianases, gerido pela administração direta) a aproximadamente R 70 milhões (no Hospital Geral de Itaim Paulista, gerido por uma Organização Social).

\section{Destaques do relatório da CPI/Alesp (2008)}

Na CPI da Remuneração dos Serviços Médico-Hospitalares da Assembleia Legislativa do Estado de São Paulo (Alesp), foi aprovada a criação de uma sub-relatoria com "o objetivo de analisar os contratos firmados entre o Estado 
e as Organizações Sociais que administram sob sistemática privada unidades hospitalares que são, em origem, públicas" (São Paulo, 2008, p. 4).

Diferente do estudo do TCE, o relatório apresentado à CPI não buscou comparar os modelos de gestão. Integrantes da CPI realizaram visitas a sete hospitais gerenciados por OS (de um total de treze), garantindo que todas as sete Organizações Sociais fossem visitadas, com exceção dos estabelecimentos gerenciados pela SPDM (Sociedade Paulista para o Progresso da Medicina), que negou essa possibilidade.

Entre os hospitais visitados pela CPI, três também foram analisados pelo estudo do TCE: Hospital Geral de Itaquaquecetuba, Hospital Geral de Itaim Paulista e Hospital Geral do Grajaú.

Dos sete hospitais visitados, verificou-se que em nenhum deles a contratação de empresas terceirizadas era feita por licitação. Em todos os casos eram contratadas empresas terceirizadas a partir de uma escolha por parte do gestor, sem necessidade de justificativa.

Ainda sobre a terceirização, três hospitais sequer forneceram a relação das empresas terceirizadas contratadas, mostrando falta de transparência, desorganização e indisposição em colaborar com uma investigação realizada por uma CPI. Isso também aconteceu nos hospitais da administração direta visitados, visto que não foram respondidos os ofícios enviados à Secretaria Estadual de Saúde em que eram solicitados esses dados.

Em todos os estabelecimentos visitados também havia terceirização da assistência médica, a partir da contratação de empresas da área de anestesiologia, neurocirurgia, cardiologia, ortopedia e oftalmologia, configurando um descumprimento das decisões do Tribunal Superior do Trabalho (TST) que proíbem a terceirização de "atividades-fim".

Do ponto de vista do acesso da população a esses hospitais, as visitas verificaram que em três deles o pronto-socorro funcionava no sistema fechado, ou seja, só era possível o acesso a partir de um encaminhamento de Unidade Básica de Saúde.

Contudo, mais do que apontar números e dados acerca dos hospitais, o parecer da sub-relatoria da CPI buscou apontar outros elementos, como a qualidade 
do serviço e condições de trabalho no âmbito das Organizações Sociais. No parecer, é apontado que

A simples análise dos contratos de gestão, dos relatórios de execução ou da prestação de contas não é suficiente para garantir a transparência. Isso porque tais documentos contêm informações muitas vezes pouco específicas, e a composição dos Conselhos de Administração e de acompanhamento da execução do contrato é constituída, em sua maioria, por membros indicados ou pelas próprias Organizações Sociais ou pelo secretário estadual de Saúde. (São Paulo, 2008, p. 42)

O parecer do sub-relator da CPI, deputado Raul Marcelo, concluiu que o "problema da qualidade e precariedade da saúde pública à população do Estado persiste", mesmo após dez anos de implementação da "solução" administrativa (São Paulo, 2008, p. 46). Ainda que os relatórios oficiais da Secretaria Estadual de Saúde mostrassem maior produtividade nos hospitais geridos pelas Organizações Sociais (o que é contraditado pela comparação feita pelo estudo do TCE), o acesso à saúde está longe de ser uma questão resolvida no âmbito do estado de São Paulo.

Por fim, o parecer ainda apresentava uma discussão acerca da existência de grande rotatividade dos trabalhadores do setor público da saúde, que seria maior nas OS em função da falta de estabilidade oriunda do contrato por CLT, diferente do regime de contratação por concurso público realizado pela administração direta.

A supressão desse parecer recebeu quatro votos favoráveis e três contrários. Contudo, consta como anexo ao final do relatório oficial da CPI.

Mesmo rejeitado, o documento foi enviado a diversos órgãos de controle e fiscalização, possibilitando que seu conteúdo fosse utilizado para abertura de novos procedimentos investigatórios.

Os relatórios do TCE e da CPI da Alesp são fruto de diferentes intenções, mas se inserem no mesmo contexto: compreender os problemas da saúde pública brasileira, buscando apontar soluções e orientações. Além do mesmo contexto, há questões similares apontadas pelos dois estudos.

O relatório elaborado pelo TCE parte de informações do próprio governo estadual, visando comparar os modelos de gestão da administração direta e o 
das Organizações Sociais. Tal perspectiva limita a análise, visto que esses dados e informações não são confrontados com outras fontes, bem como não houve construção de dados e informações por parte do próprio Tribunal de Contas.

Ainda no estudo do Tribunal de Contas, o foco está centrado numa análise quantitativa, sem preocupação quanto à qualidade do atendimento resultante da utilização de recursos públicos. Além disso, a análise de alguns indicadores hospitalares, como a taxa de mortalidade e a taxa de altas/leitos, é bastante complexa, posto que esses índices podem camuflar a seleção de casos para internação e a execução de tratamento com menor custo financeiro direto (Travassos, Noronha e Martins, 1999; Bittencourt, Camacho e Leal, 2006).

Outros pontos levantados por esse estudo também ficam incompletos, pois não há uma conclusão e/ou uma comparação. É o caso do "indicador de recursos humanos", que aponta um número maior de enfermeiros e médicos por leito nos hospitais vinculados à administração direta. Mas, ao colocar essa taxa apenas de modo genérico, não é possível concluir se ocorre um quadro de superexploração do trabalho no âmbito das Organizações Sociais ou se se trata de um caso de ociosidade no âmbito da administração direta.

Já a análise feita pela sub-relatoria da CPI da Alesp trouxe outros elementos, propiciados pelas visitas aos locais analisados e pelo material colhido em entrevistas e conversas com usuários e trabalhadores do SUS. Ainda assim, foi um estudo focado na fiscalização do uso quantitativo dos recursos públicos. Foram levantadas outras questões, como a falta de confiabilidade nas informações oriundas dos Conselhos de Administração das Organizações Sociais, visto que são órgãos formados apenas por representantes do governo e das instituições. Apesar de cumprirem estritamente o que está na lei das Organizações Sociais, a sub-relatoria considerou tais informações insuficientes do ponto de vista da confiabilidade, considerando a afinidade de posições políticas entre os administradores das OS e os membros do governo estadual de São Paulo.

Há, ainda, elementos importantes para uma efetiva melhoria do Sistema de Saúde no estado. Um deles é o apontamento da alta rotatividade da força de trabalho, tanto na administração direta quanto nas Organizações Sociais. Essa rotatividade ocorre de diferentes formas, visto que, na administração direta, ela é maior entre médicos e enfermeiros (que são profissionais que têm melhor 
remuneração no mercado privado de trabalho do que no serviço público) e, nas Organizações Sociais, ela é maior entre os demais profissionais da saúde, visto que estes recebem um melhor salário no serviço público do que na iniciativa privada.

Em síntese, o desenvolvimento de sucessivas investigações sobre o tema da gestão no SUS demonstra que o problema da saúde pública no Brasil está longe de ser resolvido. O Sistema de Saúde brasileiro continua convivendo com baixos salários (evidenciado pela alta rotatividade), uso da esfera pública para benefício privado (demonstrado pela ausência de licitações para contratação de empresas terceirizadas) e desperdício dos recursos públicos aplicados na área da saúde. Todos esses pontos deveriam ter sido, segundo os formuladores da publicização do Estado, transformados a partir da aplicação do modelo de gestão por Organizações Sociais.

\section{Discussão}

No presente trabalho o Sistema de Saúde brasileiro foi analisado a partir do recorte da gestão por Organizações Sociais no estado de São Paulo, traçando um caminho que buscou entender a situação da política pública de saúde no Brasil, tomando como objeto, no período histórico mais recente, o papel dos órgãos de controle face ao modelo de gestão por OS implementado no setor público de saúde.

Além desse percurso, foram trazidos para o âmbito acadêmico documentos cuja utilização não é comum. As fontes utilizadas abrangeram desde artigos científicos, dissertações e teses produzidas dentro de áreas diversificadas, como o campo da Saúde Coletiva, a Economia, o Serviço Social e as Ciências Sociais, como também a análise propriamente dita dos documentos elaborados pelo Tribunal de Contas do estado e pela CPI da Alesp.

Ainda que alguns aspectos não tenham sido aprofundados, especialmente os impactos epidemiológicos da gestão por Organizações Sociais, o trabalho procurou abarcar e articular alguns dos conteúdos típicos do campo da Saúde Coletiva.

Sinaliza-se a urgência de se retomar o debate sobre os princípios fundantes da Reforma Sanitária, como meio de tentar superar os problemas atuais do 
Sistema Único de Saúde. Para isso, entende-se que é preciso, mais do que nunca, repolitizar o debate no campo sanitário e retomar a exigência do financiamento integral da atenção à saúde, sob pena de futuras mudanças e proposições serem inúteis do ponto de vista da resolução dos problemas. Diferentes pesquisadores abordam o tema da apropriação do fundo público pelo capital com consequente retração das políticas de bem-estar social; dentro dos limites dados pela ordem do capital, o SUS, como ensaio do Estado de Bem-Estar Social brasileiro, não poderá se constituir genuinamente, pois isso pressupõe uma transformação radical na forma de produzir e distribuir a riqueza (Behring, 2015; Mendes, 2014; Behring e Boschetti, 2011; Salvador, 2010).

Durante o transcurso desse estudo, a gestão via Organizações Sociais esteve por diversos momentos em evidência nos meios de comunicação. Com frequência foi associada a casos de corrupção e de má gestão do recurso público (Santa, Silveira e Calsavara, 2012). Em outras ocasiões, foi objeto de grande contestação por parte de sindicatos e movimentos sociais. Analisando a regulação da gestão por OS dos serviços municipais de saúde exercida pela Secretaria Municipal de Saúde de São Paulo, Contreras e Matta concluíram que "pode-se afirmar que a administração gerencial baseada no setor privado está longe de cumprir suas principais promessas: a eficiência — que por definição exige um controle financeiro estrito - e a blindagem contra o patrimonialismo" (2015, p. 295). Tais fatos reforçaram a atualidade dessa pesquisa e também a importância das críticas aqui contidas.

Distanciando-se das promessas de mudar os paradigmas da gestão em saúde e da forma de funcionamento do Estado brasileiro, a gestão por Organizações Sociais acentuou alguns problemas já presentes na esfera pública, como os casos frequentes de corrupção e o uso da esfera pública para benefício privado, como apontam as reportagens do G1 (2015), Leme (2012), Santa, Silveira e Calsavara (2012), e ficou longe de avançar para um sistema de saúde tal como está descrito e previsto na Constituição de 1988, com acesso universal, atendimento integral e, especialmente, com políticas de prevenção de agravos e promoção da saúde.

Os documentos analisados apontaram que o modelo de gestão por Organizações Sociais apresentava maiores custos para o poder público, não garantia melhora nos índices epidemiológicos, pagava piores salários para os profissionais 
da saúde não médicos, fazia contratações sem licitação e servia como um mecanismo de transferência de recursos públicos para estabelecimentos privados da área.

As Organizações Sociais vêm contribuindo para a adaptação do Estado brasileiro ao modelo neoliberal hegemônico em outros países. A adesão ao modelo serviu para mostrar aos "investidores externos" que os governos estavam dispostos a efetivar as tais reformas gerenciais, ainda que isso pudesse gerar desgastes com segmentos importantes da população. Por outro lado, o movimento de resistência, face a essas mudanças na gestão no setor público de saúde e aos problemas que caracterizaram a gestão por OS ao longo desses anos, ainda que pequeno, teve como resultado certa restrição da aplicação desse modelo para a esfera da educação e da cultura.

Também em decorrência das denúncias de corrupção, outros modos de terceirização da gestão em saúde passaram a ser implementados, como as fundações estatais de direito privado e as empresas públicas, como a Empresa Brasileira de Serviços Hospitalares (EBSERH). Ainda que de modo mais controlado pelo Estado, esses dois modelos trazem aspectos muito semelhantes à gestão por OS: gerencialismo, flexibilidade na forma de contratação dos trabalhadores, esvaziamento do controle social e maiores possibilidades de contratação de serviços privados (Junqueira, 2000).

Os documentos analisados neste estudo evidenciaram que a opção pelas OS não foi uma escolha técnica. As OS foram fruto de um processo global de mudanças no capitalismo e de aplicação do receituário neoliberal (Bravo e Correia, 2012; Bravo, 2011). Segundo essas autoras, foram parte de um processo de ajuste no papel do Estado, fruto da hegemonia liberal, que conseguiu convencer grandes parcelas da população e dos governos de que a crise fiscal era também uma crise do Estado e que este precisava ser diminuído, a partir de "reformas gerenciais". E, mesmo dentro do paradigma gerencialista e liberal, o modelo de Organizações Sociais é defendido de modo tímido, visto que muitos pontos negativos estão a ele associados.

Dentro da nova etapa do capitalismo e da demanda pela manutenção das taxas de lucro anteriores à crise dos anos 1970, o modelo de OS excluiu do âmbito do Estado diversos serviços que eram quase que exclusivamente efetuados pela esfera estatal. Na maior parte dos países europeus, em áreas que até então 
eram objeto de gestão exclusiva por parte do Estado, o setor privado passou a predominar, conseguindo se apropriar crescentemente do fundo público (Paulo Netto, 2012; Chesnais, 2005). A gestão por OS serviu, então, como uma das formas de compensação por essa perda de lucratividade no âmbito geral (Bravo e Correia, 2012; Bravo, 2011).

No Brasil, ainda que por vias diferentes, visto que a implementação do neoliberalismo sobreveio num segundo momento, especialmente a partir de meados dos anos 1990, esse processo também ocorreu. O caminho foi aberto a partir do desmonte das políticas sociais que haviam sido recentemente sacramentadas na Constituição de 1988. Esse desmonte continua, tanto no âmbito da saúde, com a descaracterização cada vez maior do SUS, quanto em outras áreas, como educação e Previdência Social.

Ainda que não tenha sido o objeto principal deste estudo, que priorizou a crítica ao modelo por Organizações Sociais, vale ressaltar que há, sim, outras opções para a gestão da saúde e da administração pública. Nos primeiros anos de implementação do SUS, houve significativa ampliação da rede assistencial estatal, gerida de forma direta. Na maior cidade do país, São Paulo, o governo de Luiza Erundina (Partido dos Trabalhadores - PT), de 1989 a 1992, teve como uma de suas características a adoção de uma gestão descentralizada na área de saúde, incluindo aí uma autonomia financeira para as regionais e distritos de saúde que faziam a gestão da saúde descentralizada e democratizada "na ponta" (Junqueira, 2001).

O fato é que a gestão por administração direta não impede nenhum dos objetivos explícitos supostamente advindos da gestão por Organizações Sociais. Não impede o aumento de salários dos trabalhadores, não impede a contratação de contingente emergencial de trabalhadores ou a ampliação de recursos para a área. Contudo, dificulta alguns objetivos implícitos, como a transferência de recursos públicos para a iniciativa privada.

$\mathrm{Na}$ administração direta há mecanismos de controle e também mecanismos que permitem a flexibilização de formas de contratação e compras, como, por exemplo, em momentos nos quais isso é necessário. Uma gestão cuja opção política prioritária seja a administração direta pode planejar as compras de medicamentos, equipamentos e insumos de modo a evitar o esgotamento 
desses itens. Portanto, operando com recursos logísticos eficazes, a reposição de estoques, evita-se que haja falta de materiais. Além disso, as leis que regem as compras públicas, tanto nas esferas locais quanto na nacional, dispensam o uso de licitações em situações de emergência.

Ainda sobre a administração direta, é importante ressaltar que a forma de contratação dos trabalhadores, pela via do concurso público, permite o combate ao patrimonialismo (devido à forma de ingresso ser impessoal e objetiva), a participação efetiva nos espaços de controle social e a autonomia profissional (devido à estabilidade).

Dificuldades se interpuseram no desenvolver da pesquisa, notadamente o acesso a dados completos e detalhados sobre a gestão pelas OS, que deveriam estar disponíveis a qualquer cidadão nas páginas eletrônicas dos órgãos de controle, evidenciando os limites do controle externo, tanto em termos estruturais (pela própria formação do Estado brasileiro), quanto pelas suas atribuições constitucionais. Apesar da demonstração evidente de que as Organizações Sociais são um modelo mais caro e de qualidade questionável quando comparado à administração direta, a situação não foi alterada após cinco anos de elaboração dos documentos que foram objeto de estudo. Ao contrário, confrontando as evidências, o modelo de gestão por Organizações Sociais foi ampliado nesse período.

Recebido em 11/11/2016 - Aprovado em 13/6/2017

\section{Referências bibliográficas}

ANDREAZZI, M. F. S.; BRAVO, M. I. S. Privatização da gestão e organizações sociais de saúde. Trabalho, educação e saúde (Impresso), v. 12, p.499-528, 2014. Disponível em: <http://www.scielo.br/pdf/tes/v12n3/1981-7746-tes-12-03-00499.pdf >. Acesso em: 17 maio 2014.

BAHIA, L. As contradições entre o SUS universal e as transferências de recursos públicos para os planos e seguros privados de saúde. Ciência e Saúde Coletiva, Rio de Janeiro, v. 13, n. 5, p. 1385-1397, set.-out. 2008. 
BEHRING, E. R. Política social no capitalismo tardio. 6. ed. São Paulo: Cortez, 2015. ; BOSCHETTI, I. Politica social: fundamentos e história. 9. ed. São Paulo: Cortez, 2011.

BITTENCOURT, S. A.; CAMACHO, L. A. B.; LEAL, M. do C. O sistema de informação hospitalar e sua aplicação na saúde coletiva. Cadernos de Saúde Pública, Rio de Janeiro, v. 22, n. 1, p. 19-30, jan. 2006. Disponível em: <http://www.scielo.br/pdf/\%0D/csp/ v22n1/03.pdf>. Acesso em: 12 jul. 2016.

BRASIL. Presidência da República, Casa Civil, Lei n. 9.637 de 15 de maio de 1998.

BRAVO, M. I. S. Frente nacional contra a privatização e sua luta em defesa da saúde pública estatal. Serviço Social \& Sociedade, São Paulo, n.105, p.185-187, mar. 2011. Disponível em: <http://www.scielo.br/pdf/sssoc/n105/12.pdf>. Acesso em: 8 maio 2016.

BRAVO, M. I. S.; CORREIA, M. V. C. Desafios do controle social na atualidade. Serviço Social \& Sociedade, São Paulo, n.109, p.126-150, mar. 2012. Disponível em: <http:// www.scielo.br/pdf/sssoc/n109/a08n109.pdf>. Acesso em: 8 maio 2015.

CHESNAIS. F. A finança mundializada. São Paulo: Boitempo, 2005.

CISLAGUI, J. F. Hospitais universitários: presente caótico e futuro incerto. 2010. Disponível em: < https://rive.google.com/file/d/0B55E03eNUSwpWjIzdXp6MllTQ3 1YcEpxb 016bUFydw/view>. Acesso em: 8 maio 2015.

CONEGLIAN, R. Sofrimento mental como sentinela: possibilidades para a construção de um observatório das repercussões psicossociais na gestão municipal do trabalho no SUS. Dissertação (Mestrado) — Departamento de Medicina Preventiva, Unifesp, São Paulo, 2013.

CONTRERAS. H.; MATTA, G. C. Privatização da gestão do sistema municipal de saúde por meio de organizações sociais na cidade de São Paulo, Brasil: caracterização e análise da regulação. Cadernos de Saúde Pública, Rio de Janeiro, v. 31, n. 2, p. $285-$ 297, fev. 2015. Disponível em: <http://www.scielosp.org/pdf/csp/v31n2/0102-311Xcsp-31-02-00285.pdf>. Acesso em: 4 maio 2015.

CORREIA, M. V. C. Por que ser contra aos novos modelos de gestão do SUS? In: BRAVO, Maria Inês Souza; MENEZES, Juliana Souza Bravo de (Orgs.). Saúde na atualidade: por um Sistema Único de Saúde estatal, universal, gratuito e de qualidade. Rio de Janeiro: Uerj, Sirius, 2011. p. 43-49. 
DATAFOLHA. Opinião sobre as manifestações. PO813693, 21 jun. 2013. Disponível em: $<$ http://media.folha.uol.com.br/datafolha/2013/06/24/opiniao-sobre-as-manifestacoes. pdf $>$. Acesso em: 22 jun. 2013.

GRANEMMAN, S. Fundações estatais: Projeto de estado do capital. 2009. Disponível em: $<$ http://www.sinsprev.org.br/documentos/Leon/fundacoesestatais_sara.pdf $>$. Acesso em: 14 jun. 2012.

G1. Desvios da Saúde no MA passam de R \$1 bilhão, afirma delegado da PF. Disponível em: <http://g1.globo.com/ma/maranhao/noticia/2015/11/desvios-da-saude-no-mapassam-de-r-1-bilhao-afirma-delegado-da-pf.html. Acesso em: 12 jul. 2016.

JUNQUEIRA, V. Organizações sociais e as fundações estatais de direito privado: duas faces da contra-reforma de Estado. Temporalis. Revista da Abepss, São Luís, ano I, n. 1, jan.-jun. 2000.

. Saúde na cidade de São Paulo (1989 a 2000). São Paulo: Polis, PUC-SP, $2001.56 \mathrm{p}$.

LEME, C. Hospitais públicos de SP gerenciados por OS: rombo acumulado é de R\$ 147,18 milhões. 2012. Disponível em: <http://www.viomundo.com.br/denuncias/ hospitais-publicos-de-sp-gerenciados-por-oss-a-maioria-no-vermelho.html>. Acesso em: 10 out. 2012.

MENDES, A. N. O fundo público e impasses do financiamento da saúde universal brasileira. Saúde e Sociedade, São Paulo, v. 23, n. 4, p.1183-1197, 2014. Disponível em: <http://www.scielo.br/pdf/sausoc/v23n4/0104-1290-sausoc-23-4-1183.pdf>. Acesso em: 27 ago. 2015.

MONTAÑO, C. Terceiro setor e questão social: crítica ao padrão emergente de intervenção social. São Paulo: Cortez, 2002.

OCKÉ-REIS, C. E.; ANDREAZZI, M. L. F.; SILVEIRA, F. G. O mercado de planos de saúde no Brasil: uma criação do Estado? IPEA. Texto para discussão n. 1094, Rio de Janeiro, jun. 2005. Disponível em: $<$ http://desafios2.ipea.gov.br/agencia/images/ stories/PDFs/TDs/td_1094.pdf>. Acesso em: 20 set. 2015.

PAULO NETTO, J. Crise do capital e consequências societárias. Serviço Social \& Sociedade, São Paulo, n.111, p. 413-429, set. 2012. Disponível em: <http://www.scielo. br/pdf/sssoc/n111/a02.pdf $>$. Acesso em: 27 ago. 2015. 
SALVADOR, E. Fundo público e seguridade social no Brasil. São Paulo: Cortez, 2010. SANTA, A.; SILVEIRA, F.; CALSAVARA, F. Barbosa Neto tem o mandato cassado em Londrina. Gazeta do Povo, Curitiba, 30 jul. 2012. Disponível em: <http://www. gazetadopovo.com.br/vida-publica/barbosa-neto-tem-o-mandato-cassado-em-londrina1zxyfoq6hnjkqwtei8i3lro0e>. Acesso em: 12 jul. 2016.

SÃO PAULO. Assembleia Legislativa do Estado de São Paulo. Gabinete do deputado estadual Raul Marcelo. Ofício RMS 021/2008.

. Poder Executivo, Lei Complementar n. 846 de 4 de junho de 1998.

. Tribunal de Contas do Estado. Comparação de hospitais estaduais paulistas: estudo comparativo entre gerenciamento da administração direta e das organizações sociais da saúde. 2010. Disponível em: <https://www4.tce.sp.gov.br/6524-tribunaldisponibiliza-estudo-comparativo-entre-o-gerenciamento-da-administracao-direta-dos $>$. Acesso em: 12 jul. 2015.

TANAKA, O. Y.; MELO, C. (Orgs.), Inovação e gestão: a organização social no setor saúde. São Paulo: Annablume/Fapesp, 2002.

TRAVASSOS, C.; NORONHA, J. C.; MARTINS, M.; Mortalidade hospitalar como indicador de qualidade: uma revisão. Ciência \& Saúde Coletiva, Rio de Janeiro, v. 4, n. 2, p. 367-381, 1999. Disponível em: <http://www.scielo.br/pdf/\%0D/csc/v4n2/7119. pdf $>$. Acesso em: 12 jul. 2015.

TRIVIÑOS, A. N. S. Introdução à pesquisa em Ciências Sociais: a pesquisa qualitativa em educação. São Paulo: Atlas, 1987. 175 p. 